\title{
The Effects of Nanoclay on Mechanical Properties of High Density Polyethylene and Polypropylene Materials
}

\author{
E. AKDOĞAN ${ }^{a, b}$ AND N.B. BEKTAŞ ${ }^{a, *}$ \\ ${ }^{a}$ Pamukkale University, Faculty of Engineering, Department of Mechanical Engineering, Denizli 20160, Turkey \\ ${ }^{b}$ Karamanoğlu Mehmetbey University, Faculty of Engineering, Department of Mechanical Engineering, \\ Karaman 70100, Turkey

\begin{abstract}
Polymeric materials find usage in most places in daily life. Expected features vary depending on the use of these materials. Composite material can be formed by combining one or more different materials. Physical and chemical properties of a new produced composite material can be improved with the addition of additives and fillers to polymer materials. The addition of additives and fillers improve one or more properties at the same time, despite that, it may lead to deteriorate another property. Therefore, it is necessary to investigate the mechanical and thermal properties of these produced composite structures. This study was carried out by nanoclay addition to high density polyethylene (HDPE) and polypropylene (PP) materials. Nanoclay additions were made to the polymer matrix at mass ratios of $5 \%$ and $10 \%$. Tensile test, tear test and the Izod impact tests were performed. It has been observed that the tensile strengths of HDPE composites decreased whereas PP composites increased with respect to the pure products. Also, the tear strengths of composites decreased compared to pure products. In the Izod impact tests, all notched specimens were broken. The values of impact strength of the PP composites were not changed in the notched Izod impact tests, whereas the HDPE composites showed a decrease.
\end{abstract}

DOI: 10.12693/APhysPolA.134.297

PACS/topics: high density polyethylene, polypropylene, tensile strength, tear strength, impact resistance

\section{Introduction}

The diversity of product range, easy manufacturability, low cost and different features combined together of polymeric materials which make their usage areas has increased considerably in recent years. These materials which are often petroleum-based that called engineering plastics, their costs need to be reduced and some of their properties must be improved. The mechanical and thermal properties of the polymer matrix can be improved by adding organic and inorganic materials at different ratios in literature studies [1-3]. In addition, the cost of polymer materials can be reduced by adding fillers. The compatibility and particle size of these additives in the polymer matrix affect the properties of the polymer composite [4]. As the particle size increases, the mechanical properties of the polymer material decrease and therefore it is emphasized that the importance of using smaller particle sized nano-additives and fillers to nanomaterials. These materials which are called polymer nanocomposite, the particles are spread in more homogeneous form because of the nanoscale size of particles in the polymer matrix and better holding can be achieved as the surface area is increased $[5,6]$. Several studies have been carried out to improve the mechanical and thermal properties of the polymer matrix adding nanoparticles with suitable compatibilizer [5-9]. It has been observed that the Izod impact resistance is reduced by nanosized particle reinforcement to polymeric materials $[8,10]$. However, it is

*corresponding author; e-mail: nbbektas@pau.edu.tr seen that these properties can be improved with different compatibilizer $[8,11]$. As can be seen clearly from the literature, tensile strengths and modulus of elasticity values can be increased with the addition of nanoclay to the polymer matrix [8].

In this study, HDPE and PP polymer matrices were produced by nanoclay addition at mass ratios of $5 \%$ and $10 \%$. Mechanical properties of produced nanocomposites have been obtained to investigate the effects of nanoclay additions. The production of HDPE and PP polymers with and without nanoclay additives were always carried out under the same conditions.

\section{Experimental}

\subsection{Materials}

In this study, the polymer matrix with melt flow rate $5.5 \mathrm{~g} / 10 \mathrm{~min}\left(190^{\circ} \mathrm{C} / 2.16 \mathrm{~kg}\right)$ of HDPE having density of $0.965 \mathrm{~g} / \mathrm{cm}^{3}$ and melt flow rate $4.7 \mathrm{~g} / 10 \mathrm{~min}$ $\left(230^{\circ} \mathrm{C} / 2.16 \mathrm{~kg}\right)$ PP having density of $0.905 \mathrm{~g} / \mathrm{cm}^{3}$ were used. Petilen YY I 668 and Petoplen MH 418 commercial products were suitable for injection molding with HDPE and PP, respectively. HDPE and PP materials in a granular form were supplied from Petkim Inc. (İzmir, Turkey). Nanoclay filler material was get from Nanokil Ltd. Co. (Erzurum, Turkey). The nanoclay has a grain size of $1-200 \mathrm{~nm}$ and contains mass of $6.13 \% \mathrm{Fe}_{2} \mathrm{O}_{3}, 20.67 \% \mathrm{Al}_{2} \mathrm{O}_{3}, 53.28 \% \mathrm{SiO}_{2}, 2.82 \% \mathrm{MgO}$, $1.71 \% \mathrm{CaO}, 0.02 \% \mathrm{Na}_{2} \mathrm{O}, 0.82 \% \mathrm{~K}_{2} \mathrm{O}, 0.63 \% \mathrm{TiO}_{2}$. The granules were coated with polydimethylsiloxane (PDMS) to spread the nanoclay filler homogeneously. Siltech F-12500 was used for PDMS which is the product of Siltech Co. (Toronto, Canada). 


\subsection{Specimen preparation}

The surface of the granules was coated with PDMS by pre-mixing. The nanoclay additives were added to matrix in $5 \%$ and $10 \%$ mass proportions given in Table I and mixed for 5 min at $200 \mathrm{rpm}$ with a mechanical stirrer. Then, the mixtures were dried at $100^{\circ} \mathrm{C}$ for $2 \mathrm{~h}$ and ready for molding by injection. The blended mixtures products were transferred from the feeding zone to the nozzle zone by the injection molding at $160-170-180-190^{\circ} \mathrm{C}$ temperatures. The mold temperature was set at $40^{\circ} \mathrm{C}$. The screw diameter of the injection machine is $35 \mathrm{~mm}$ and the $L / D$ ratio is 30 . From each mixture, 20 specimen groups were produced. There are tensile test specimens, notched and un-notched Izod impact test specimens, UL94 test specimens, tear test specimens and cone calorimeter test specimens in these specimen groups.

Composition of blends and composites in wt\%. TABLE I

\begin{tabular}{c|c|c|c|c}
\hline \hline Abbreviation & HDPE [\%] & PP [\%] & PDMS [\%] & NC [\%] \\
\hline PE & 100 & - & - & - \\
PE-Sil & 100 & - & 1 & - \\
PE-05NC & 95 & - & 1 & 5 \\
PE-10NC & 90 & - & 2 & 10 \\
PP & - & 100 & - & - \\
PP-Sil & - & 100 & 1 & - \\
PP-05NC & - & 95 & 1 & 5 \\
PP-10NC & - & 90 & 2 & 10
\end{tabular}

\subsection{Tests and characterization}

Tensile tests, tear tests and the Izod impact tests were carried out to determine the mechanical properties. The dimensions of the test specimens were arranged to standards of ASTM D-638 (Type IV) for the tensile test, ASTM D-624 (Type-T) for the tear test and ASTM D256 for the Izod impact test. Tensile and tear tests were carried out on Tinius Olsen H10KT universal test equipment at a speed of $50 \mathrm{~mm} / \mathrm{min}$. The specimens were kept for $40 \mathrm{~h}$ at $23^{\circ} \mathrm{C}$ and $50 \%$ relative humidity before the experiment. For the Izod impact tests, it was carried out at $-40,-20$, and $23^{\circ} \mathrm{C}$ for $40 \mathrm{~h}$, respectively. Impact resistance is measured with a $7.5 \mathrm{~J}$ hammer on the CEAST Resil Impactor device. Five specimens were used for each test.

\section{Results and discussion}

Tensile tests were performed to observe the effect of additives NC and PDMS on the mechanical properties. The effects of adding PDMS and NC to HDPE and PP polymers on tensile strength and modulus of elasticity are seen in Fig. 1a with comparing each composites. The average, maximum and minimum ranges of tensile strength, young modulus, tear strength and impact resistance values of composites are seen in Table II. Addition of PDMS to the polymer matrix resulted in a slight decrease in tensile strength and modulus of elasticity. It was determined that tensile strength and modulus of elasticity values of PE-05NC specimens decreases by $14 \%$ and $12.6 \%$ respectively, whereas modulus of elasticity values of PE-10NC specimens increased by $5 \%$. It is observed that the modulus of elasticity values of PE-10NC specimen is higher than that of the pure ones. Tensile strength and modulus of elasticity values increased regularly as NC ratio increased for PP composites. However, it is seen that PDMS addition to PP, tensile strength, and modulus of elasticity values decrease with respect to pure one.
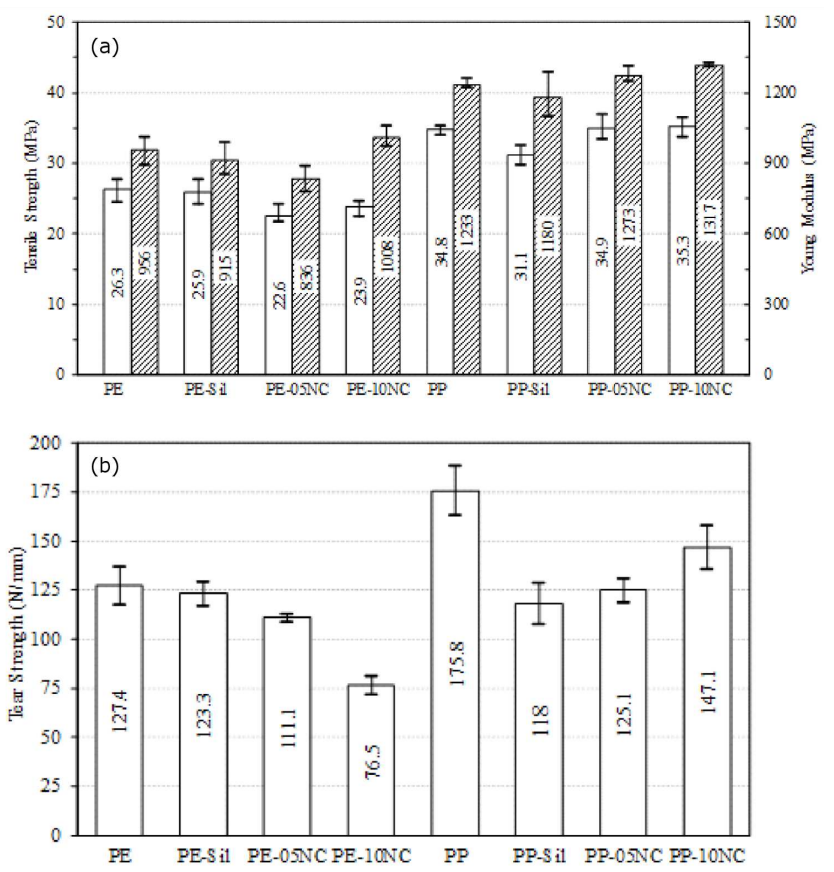

Fig. 1. Comparison of (a) tensile strength $\square$ and the. Young modulus $\square$ and (b) tear strengths $\square$ of $\mathrm{HDPE} / \mathrm{NC}$ and $\mathrm{PP} / \mathrm{NC}$ composites
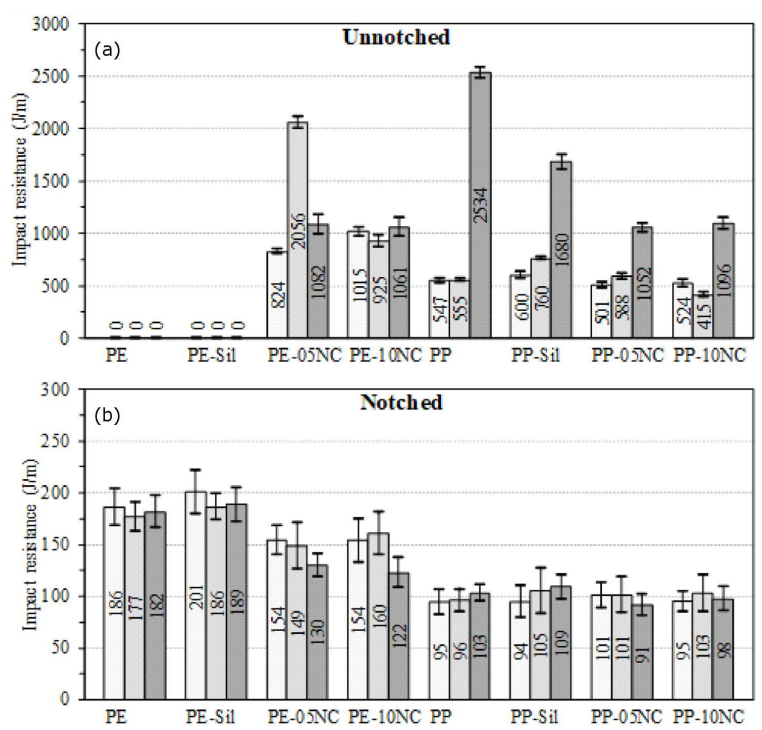

Fig. 2. Comparison of impact resistance of (a) unnotched and (b) notched $\mathrm{HDPE} / \mathrm{NC}$ and $\mathrm{PP} / \mathrm{NC}$ composites at -40()$,-20(\square)$ and $23(\square){ }^{\circ} \mathrm{C}$. 
Tensile strength, the Young modulus, tear strength and impact resistance values of composites.

TABLE II

\begin{tabular}{|c|c|c|c|c|c|c|c|c|c|}
\hline \multirow{3}{*}{ Sample } & \multirow{3}{*}{$\begin{array}{c}\text { Tensile } \\
\text { strength } \\
{[\mathrm{MPa}]}\end{array}$} & \multirow{3}{*}{$\begin{array}{c}\text { Young } \\
\text { modulus } \\
{[\mathrm{MPa}]}\end{array}$} & \multirow{3}{*}{$\begin{array}{c}\text { Tear } \\
\text { strength } \\
{[\mathrm{N} / \mathrm{mm}]}\end{array}$} & \multicolumn{6}{|c|}{ Impact resistance $[\mathrm{J} / \mathrm{m}]$} \\
\hline & & & & \multicolumn{3}{|c|}{ Unnotched } & \multicolumn{3}{|c|}{ Notched } \\
\hline & & & & $-40^{\circ} \mathrm{C}$ & $-20^{\circ} \mathrm{C}$ & $23^{\circ} \mathrm{C}$ & $-40^{\circ} \mathrm{C}$ & $-20^{\circ} \mathrm{C}$ & $23^{\circ} \mathrm{C}$ \\
\hline $\mathrm{PE}$ & $26.3 \pm 1.5$ & $956 \pm 61$ & $127.4 \pm 9$ & - & - & - & $186 \pm 18$ & $177 \pm 14$ & $182 \pm 16$ \\
\hline PE-Sil & $25.9 \pm 1.7$ & $915 \pm 68$ & $123.3 \pm 6$ & - & - & - & $201 \pm 21$ & $186 \pm 13$ & $189 \pm 17$ \\
\hline PE-05NC & $22.6 \pm 1.3$ & $836 \pm 56$ & $111.1 \pm 2$ & $824 \pm 24$ & $2056 \pm 55$ & $1082 \pm 93$ & $154 \pm 14$ & $149 \pm 23$ & $130 \pm 11$ \\
\hline PE-10NC & $23.9 \pm 1.1$ & $1008 \pm 43$ & $76.5 \pm 5$ & $1015 \pm 38$ & $925 \pm 53$ & $1061 \pm 91$ & $154 \pm 21$ & $160 \pm 21$ & $122 \pm 15$ \\
\hline $\mathrm{PP}$ & $34.8 \pm 0.7$ & $1233 \pm 19$ & $175.8 \pm 13$ & $547 \pm 24$ & $555 \pm 17$ & $2534 \pm 52$ & $95 \pm 13$ & $96 \pm 11$ & $103 \pm 8$ \\
\hline PP-Sil & $31.1 \pm 1.4$ & $1180 \pm 93$ & $118 \pm 11$ & $600 \pm 31$ & $760 \pm 15$ & $1680 \pm 69$ & $94 \pm 16$ & $105 \pm 22$ & $109 \pm 12$ \\
\hline PP-05NC & $34.9 \pm 1.8$ & $1273 \pm 33$ & $125.1 \pm 6$ & $501 \pm 28$ & $588 \pm 27$ & $1052 \pm 46$ & $101 \pm 12$ & $101 \pm 18$ & $91 \pm 11$ \\
\hline PP-10NC & $35.3 \pm 1.4$ & $1317 \pm 8$ & $147.1 \pm 11$ & $524 \pm 34$ & $415 \pm 24$ & $1096 \pm 57$ & $95 \pm 10$ & $103 \pm 18$ & $98 \pm 12$ \\
\hline
\end{tabular}

Tear strength tests were performed to observe the effects of addition PDMS and NC additives on tear resistance of polymer matrix which was shown in Fig. 2b. The average, maximum and minimum range of the tear strength values are given in Table II. With addition of PDMS to HDPE polymer, there was a slight decrease by $3.2 \%$ in the tear strength, whereas a significant decrease by $32.9 \%$ was observed with the addition of PDMS to $\mathrm{PP}$ polymer. With the increased addition of NC, a considerable decrease in tear strength on HDPE composites was observed, but the respectable increase was observed in PP composites compared to PP-Sil one.

The Izod impact test results were given in Table II. It was observed that the impact resistance of HDPE and PP composites were increased by PDMS addition at all temperatures (Fig. 2). The unnotched PE and PE-Sil specimes were not broken but the other samples were broken at temperatures of $-40,-20$ and $23^{\circ} \mathrm{C}$. The impact resistance increased at $-40{ }^{\circ} \mathrm{C}$ while the $\mathrm{NC}$ ratio increased in unnotched HDPE composites. But it is decreased at $-20^{\circ} \mathrm{C}$ and decreased slightly at $23^{\circ} \mathrm{C}$. It has been found that impact resistance of notched HDPE composites increases slightly increasing amount of $\mathrm{NC}$ at $-20^{\circ} \mathrm{C}$ but impact resistance decreases compared to pure HDPE composites. A noticeable decrease was observed at $23^{\circ} \mathrm{C}$ when the impact resistance of the notched PP samples was not changed much at low temperatures. Notched PP specimen's impact resistance values increased at low temperatures. It was observed a slight decrease at $23^{\circ} \mathrm{C}$.

\section{Conclusion}

The addition of PDMS to HDPE and PP polymers reduces the tensile strength and elasticity modulus values of those. As the NC ratio in $\mathrm{HDPE} / \mathrm{NC}$ composites increases, the tensile strength and elasticity modulus values increase, but these values are lower than the pure product. As the $\mathrm{NC}$ ratio of $\mathrm{PP} \mathrm{NC}$ composites increases, tensile strength and modulus of elasticity values increase with respect to pure product. With the addition of PDMS to both composites, the tear resistance of HDPE composites decreased slightly, while the PP composites showed a significant decrease. Compared to $\mathrm{PP} /$ Sil composites, a noticeable increase in tear resis- tance was observed with increasing $\mathrm{NC}$ ratio in $\mathrm{PP}$ composites, whereas a remarkable decrease was observed in HDPE composites. All specimens were broken in the Izod impact tests except unnotched HDPE and HDPE/Sil specimens. With the addition of $\mathrm{NC}$, the impact resistance of notched HDPE composites decreased while no significant change in PP composites was observed. The addition of PDMS to polymer composites increased the impact resistance at low temperatures, whereas it reduced only notched PP composites at $23^{\circ} \mathrm{C}$.

\section{Acknowledgments}

The authors would like to thank BAP (Scientific Research Project Fund of Pamukkale University) for supporting this study under project number 2014FBE031 and also thank to Dr. Ayhan Ezdeşir from Petkim and Prof. Dr. Nazım Usta from Pamukkale University for their valuable contributions.

\section{References}

[1] N. Usta, J. Appl. Polym. Sci. 124, 3372 (2012).

[2] J.A. Morais, R. Gadioli, M.A. Paoli, Polimeros 26, 115 (2016).

[3] A. Dike, F. Mindivan, H. Mindivan, Acta Phys. Pol. A 125, 396 (2014).

[4] L. Domka, A. Malicka, N. Stachowiak, Acta Phys. Pol. A 114, 413 (2008).

[5] A. Malicka, L. Domka, Acta Phys. Pol. A 114, 423 (2008).

[6] A. Fina, F. Cuttica, G. Camino, Polym. Degrad. Stab. 97, 2619 (2012).

[7] N. Ayrilmis, Composites Part B 44, 745 (2013).

[8] A. Najafi, B. Kord, A. Abdi, S. Ranaee, J. Thermoplast. Compos. Mater. 25, 717 (2012).

[9] S. Adanur, E. Selver, Int. J. Polym. Mater. 62, 236 (2013).

[10] Y. Zhang, L. Zhang, H. Liu, H. Du, X. Li, X. Zhang, J. Zhang, J. Macromol. Sci. Phys. 53, 13 (2014).

[11] Z. Vuluga, D.M. Panaitescu, C. Radovici, C. Nicolae, M.D. Iorga, Polym. Bull. 69, 1073 (2012). 